\title{
AS POLÍTICAS PÚBLICAS DE INCLUSÃO SOCIAL EM UM BAIRRO PERIFÉRICO POBRE DE UMA CIDADE MÉDIA DA BAHIA: UM ESTUDO DAS REPRESENTAÇÕES SOCIAIS DE ESPAÇO E TEMPO
}

\author{
The public policies of social inclusion in a poor peripheral neighborhood of a middle city \\ of Bahia: a study of the social representations of space and time
}

\section{Las políticas públicas de inclusión social en um barrio periférico pobre de una ciudad media de Bahía: un estudio de las representaciones sociales de espacio y tiempo}

\author{
Francisco dos Santos Carvalho ${ }^{1}$ \\ Marcus Antônio Assis Lima ${ }^{2}$ \\ Mauro dos Santos Carvalho ${ }^{3}$
}

\footnotetext{
${ }^{1}$ Professor da Universidade Estadual do Sudoeste da Bahia (UESB), Coordenador do Grupo de Pesquisa em Inovações Tecnológicas e Modernização, e-mail: franciscodossantoscarvalho@gmail.com

${ }^{2}$ Professor Titular, Professor e Coordenador do Programa de Pós-Graduação em Letras: Cultura, Educação e Linguagens na Universidade Estadual do Sudoeste da Bahia (UESB), e-mail: malima@uesb.edu.br

${ }^{3}$ Mestrando em Educação (PPGED) na Universidade Estadual do Sudoeste da Bahia (UESB), e-mail: mauroscarvalho@yahoo.com.br
}

\begin{abstract}
Resumo
Este artigo objetivou verificar o que ficou na memória dos moradores e as representações sociais construídas ao longo do tempo, analisando as políticas públicas existentes no espaço urbano do Bairro Nosa Senhora Aparecida (NSA). Para isso, fez-se uso de procedimentos exploratórios e descritivos, com base nos enfoques descritivo e interpretativo. Inicialmente foram feitas pesquisas bibliográfica e documental. Posteriormente, foi executada uma pesquisa de levantamento. Ao final da investigação, os dados coletados evidenciaram que quase todos os domicílios do referido bairro dispõem de rede de energia elétrica e abastecimento de água, mas de modo geral, a infraestrutura física do bairro ainda é precária, caracterizada por moradias construídas na modalidade de autoconstrução. Como programas públicos ativos se destacam: o PETI, Bolsa Família e Projovem Adolescente e Urbano.
\end{abstract}

Palavras-chave: Bairro pobre; Cidade média; Políticas públicas.

\begin{abstract}
This paper aims to verify what has remained in the memory of the residents and the social representations built over time, analyzing the public policies existing in the urban space of the Neighborhood Nossa Senhora Aparecida (NSA). For this, exploratory and descriptive procedures were used, based on the descriptive and interpretative approaches. Initially bibliographical and documentary research was done. Subsequently, a survey was carried out. At the end of the investigation, the collected data showed that almost all households in this neighborhood have electric power and water supply, but in general, the physical infrastructure of the neighborhood is still precarious, characterized by housing built in the modality of self-construction. As active public programs stand out: PETI, BolsaFamilia and Projovem Adolescente e Urbano.
\end{abstract}

Keywords: Poor neighborhood; Average city; Public policy. 


\section{Resumen}

Este artículo objetivó verificar lo que quedó en la memoria de los moradores y las representaciones sociales construidas a lo largo del tiempo, analizando las políticas públicas existentes em el espacio del barrio Nossa Senhora Aparecida (NSA). Para eso, se hizo uso de procedimientos exploratorios y descriptivos, con base en los enfoques descriptivo e nterpretativo. Inicialmente se realizaron investigaciones bibliográficas y documentales. Posteriormente, se realizó una encuesta de levantamiento. Al final de la investigación, los datos recolectados evidenciaron que casi todos los domicílios del referido barrio disponen de red de energía eléctrica y abastecimiento de agua, pero de modo general, la infraestructura física del barrio aún es precaria, caracterizada por viviendas construídas em la modalidad de autoconstrucción. Como programas públicos activos se destacan: el PETI, Bolsa Familia y Projovem Adolescente y Urbano.

Palabras clave: Barrio pobre; Ciudad media; Políticas públicas.

\section{Introdução}

O resgate do passado de uma cidade mediante as representações de espaço e tempo deve levar em consideração que a temporalidade pode encontrar forma e sentido no espaço composto por múltiplas temporalidades e sentidos. É possível, com base na unidade espaçotemporal, analisar o passado de um povo ou de um aglomerado de bairros por intermédio da memória e da história.

Este trabalho buscou resposta para a seguinte questão de pesquisa: Como o espaço urbano do Nossa Senhora Aparecida (NSA), bairro pobre e periférico da cidade de Vitória da Conquista, Bahia, Brasil, se articula com a memória e as representações sociais?

O objetivo concerniu em verificar o que ficou na memória de moradores do bairro NSA e as representações sociais construídas ao longo do tempo. No início do processo investigado em questão, havia uma suposição de que o espaço urbano escolhido para análise localizado em um municipio que é referência regional nos setores de educação, saúde e comércio - mantém forte inter-relação com a memória dos moradores e as representações sociais do supracitado bairro.

Foi preciso resgatar as lembranças a respeito da paisagem, como eram as ruas e as casas, pois os residentes mais antigos da localidade tinham muitas histórias para contar sobre o que existía naquela época e o que não há mais no presente, além de relatar sobre as condições da infraestrutura do passado e exibir uma visão atual da paisagem.

Ressalta-se que este trabalho possui relevância acadêmica e social, pois trata-se de uma investigação que contribui de algum modo para a descrição do espaço e das 
representações sociais no bairro-alvo de investigação, que faz parte de uma das mais importantes cidades médias do Estado da Bahia.

O método de estudo de caso foi escolhido para guiar o processo investigativo, posto ser um método que requer do(a) pesquisador(a) adaptabilidade e flexibilidade para compreender as mudanças que podem surgir durante a execução da pesquisa, a partir de novos eventos (YIN, 2005). Fundamentada no paradigma construtivista, a estratégia metodológica fez uso de análises qualitativa e quantitativa (HAGUETTE, 1997; TRIVINOS, 1997).

Fez-se uso de procedimentos exploratórios e descritivos, com base nos enfoques descritivo e interpretativo, em relação aos objetivos ou fins da pesquisa. Em uma primeira etapa, foram realizadas pesquisas bibliografia e documental. Posteriormente, foi realizada uma pesquisa de levantamento, que não é objeto de análise no presente trabalho.

Tabela 1 - Composição da amostra - Pesquisa 2010-2012.

\begin{tabular}{llll}
\hline Público-alvo & Qtde & Público-alvo & Qtde \\
\hline Domicílios do bairro NSA & 290 & Prefeito & 1 \\
SecretáriosMunicipais & 9 & Ex-Prefeitos & 5 \\
Colaboradores da Prefeitura & 15 & Especialistasempolíticaspúblicas & 22 \\
Lideranças do bairro NSA & 10 & Moradores de outros bairros & 50 \\
Estudantes & 20 & Comerciantes do bairro NSA & 15 \\
Trabalhadores do bairro NSA & 16 & & \\
\hline
\end{tabular}

Fonte: Pesquisa de campo, 2012.

A Tabela 1 contém os dados sobre os públicos-alvo da pesquisa. Ressalta-se que a coleta de dados e informações foi realizada valendo-se de diversos meios, por intermédio do uso de: Observação in loco (no bairro NSA), entrevistas semiestruturadas, registro fotográfico, levantamento e análise documental.

\section{Memória e sociedade}

Em seu livro "Memória e sociedade: lembranças de velhos”, Ecléa Bosi (BOSI, 1994) escreveu sobre a memória de velhos, trazendo nos dois primeiros capítulos as teorias, e no último capítulo, ela mesma se revelou como uma personagem narradora. É interessante que a memória foi percebida ali como uma construção de pessoas que já foram muito ativas na sociedade, sejam homens ou mulheres pertencentes um grupo social, que trabalharam e agora exercem uma nova função social, que é justamente a de lembrar e compartilhar as histórias com os jovens sobre as suas histórias de vida, de como viveram, como eram os espaços 
sociais desde a sua infância e como eles mudaram, contando ainda, sobre o que eram e o que aprenderam no decorrer do tempo.

Chauí citou na apresentação de "memória e sociedade: lembranças de velhos", um texto que foi redigido como arguição ao longo da defesa de tese de livre-docência de Ecléa Bosi, na Universidade de São Paulo, por isso, foi preferido mantê-lo na forma coloquial:

Por que temos que lutar pelos velhos? Porque são a fonte de onde jorra a essência da cultura, ponto onde o passado se conserva e o presente se repara, pois como escrevera Benjamin, só perde o sentido aquilo que no presente não é percebido como visado pelo passado [...] (CHAUÍ, 1979, p. 17).

E ainda prosseguiu:

[....] O que foi não é uma coisa revista por nosso olhar, nem é uma ideia inspecionada por nosso espírito - alargamento das fronteiras do presente, lembrança de promessas não cumpridas. Eis porque, recuperando a figura do cronista contra a do cientista da história, Benjamin afirma que o segundo é uma voz despencando no vazio, enquanto o primeiro crê que tudo é importante, conta e merece ser contado, pois todo dia é o último dia. E o último dia é hoje (CHAUÍ, 1979, p. 17).

Os mais velhos são, portanto, essenciais para resgatar as lembranças do tempo passado, e nesse processo, Bosi (1994) sinaliza que eles ainda "fazem", ou seja, não são apenas passivos, pois à medida que vão relatando as histórias, se tornam personagens ativos com ricas experiências e uma função social na velhice que é necessária para fazer história.

\section{O espaço e as representações sociais}

Analisando a literatura especializada, constatou-se que grande parte das cidades brasileiras foi constituída com base nas práticas de ocupação do espaço que não tiveram base em um planejamento urbano prévio (MAIOLINO; MANCEBO, 2005; HAESBAERT, 2011).

Ao se aprofundar na problemática de ocupação dos espaços, Santos (1996) apontou que uma cidadania seria plenamente constituída quando houvesse investimentos públicos em todos os espaços. Por sua vez, Pesavento (2005, p. 14) acrescentou que o tempo em uma cidade é múltiplo e que o direito à cidade é "“[...] fundamentalmente, um direito à história, à memória, à identidade".

Na avaliação de Pesavento (2005, p. 11), o “[...] resgate do passado implica em ir além desta instância, para os domínios do simbólico e do sensível, ao encontro da carga de significados que esta cidade abrigou em outro tempo". Complementa Pesavento (loc. cit) que há uma inter-relação entre as competências das instâncias responsáveis por compreender a 
natureza de uma memória social, conhecer as histórias por trás do traçado das ruas, da infraestrutura das praças e dos prédios. À medida que as pessoas vão relatando as histórias do passado, elas vão trazendo as representações sociais dos espaços onde vivenciaram experiências e com o tempo se modificaram.

Uma vida repleta de etapas em que os sujeitos produziram, construíram prédios, casas, trouxeram uma nova paisagem para as ruas, pontos comerciais foram abertos e outros fechados, escolas foram criadas, postes passaram a iluminar certas ruas, a água encanada chegou a diversos pontos, enfim, a cidade passa por transformações constantes, e são essas pessoas, na velhice, que terão o benefício da memória para contar as histórias, carregando as representações de cada etapa que vivenciaram. Como ratifica Bosi (1994, p. 68) "a lembrança é a história da pessoa e seu mundo, enquanto vivenciada".

Diante do exposto, as memórias e as representações sociais dos moradores do espaço urbano Nossa Senhora Aparecida se despontam como um significativo meio para uma observação geral do referido bairro, apresentando o estado atual da sua infraestrutura física, a partir da reunião de histórias e lutas daqueles que estão por trás das praças, das casas e das ruas.

A construção do bairro NSA é uma história que merece ser contada. Revela a enorme coragem e as lutas dos primeiros moradores que ocuparam aquele espaço geográfico que, até o ano de 1935, era totalmente constituído apenas pela fauna e flora nativas, um espaço natural, praticamente, sem a influência dos moradores da cidade de Vitória da Conquista.

A chegada dos primeiros moradores para um local não habitado, cercado de mato por todos os lados, sem estradas abertas, sem energia, sem água, sem transporte público, sem legislação que regulamentasse a ocupação do solo urbano, sem o olhar do Estado, sem, portanto, nenhuma ação anterior do Poder Público em termos de políticas públicas, é algo que merece ser descrito, pois tem implicação na organização e vida dos moradores.

Durante as diversas e longas entrevistas, foi identificado que o primeiro morador do bairro NSA foi o Sr. Raimundo Custódio da Silva, nascido em 1890, além de ser o primeiro proprietário de terreno daquele espaço urbano, dividindo-o em lotes que foram vendidos.

Em entrevista com o filho do citado morador, o Sr. Meneval Custódio do Nascimento, pôde-se identificar que o primeiro morador chegou ao bairro no ano de 1935, na companhia de dois irmãos, proveniente do Estado de Pernambuco.

Um trecho de uma das entrevistas com o Sr. Raimundo Custódio Neto, filho do Sr. Meneval, transcrito a seguir, resume a descrição da ocupação do espaço físico do bairro em 
termos de construção de moradias, por meio das memórias que revelou a descrição do bairro NSA quando quase tudo era só mato:

Na minha infância o bairro era só mato, terra, não tinha calçamento, nem água, nem energia. Tinha a casa da minha Avó, uma casa de adobão, uma segunda casa que meu avô construíra a casa do seu Benedito Elias dos Santos, uma primeira casa que morou um aleijado e que depois foi passada para a Dona Diolina, aqui na Rua Santa Ana, e a casa de João da Puba (informação verbal) ${ }^{1}$.

Até a conclusão da investigação, o bairro NSA possuía apenas uma escola de ensino fundamental I e II. Uma estudante da $4^{\text {a }}$ Série fez uma redação muito significativa. Escreveu que gostava bastante do bairro, mas que aquele espaço urbano precisava de mais policiais, ampliação dos serviços do Posto de Saúde NSA. Destacou também a necessidade de ampliação do acervo bibliográfico e do número de professores na referida escola. Manifestou ainda a sua preocupação com a falta de pavimentação de ruas do bairro, além de enfatizar a necessidade de implantação de áreas de lazer.

Na avaliação de Benedictis (2007, p. 15), é necessário "aprender a olhar a cidade onde vivemos". Essa é uma tarefa que envolve observação sobre a realidade material.

Ao defender o imperativo de se trabalhar a produção do espaço de cidade, Haesbaert (2007, p. 79) afirmou que era preciso ter “[...] uma visão do território a partir do espaço como híbrido entre a sociedade e natureza, entre política, economia e cultura, e entre a materialidade e a idealidade [...]". O referido autor ainda destacou que entender a materialidade e idealidade, requer complexa integração espaço-tempo.

Assim, desenvolver uma incursão com fundamento nas categorias espaço-tempo é estar ciente de que o passado e o presente mantêm interação. Não se pode separar "presente do passado, sincrônico de diacrônico, fluidez de fixação, transformação de permanência" (HAESBAERT, 2011, p. 1). O espaço ora investigado pode ser compreendido como uma relação dialética, como "condição, meio e produto da realização da sociedade humana em toda a sua multiplicidade" (CARLOS, 2001, p. 11).

No entendimento de Santos (2002), surgem novos arranjos em cada período histórico. Assim, a análise e a interpretação das práticas socioespaciais podem oferecer subsídios para um melhor entendimento da estruturação do bairro NSA.

\footnotetext{
${ }^{1}$ Entrevista concedida por CUSTÓDIO NETO, R. de. Entrevista I. [mar. 2012]. Entrevistador: Francisco Carvalho, março de 2012. 1 arquivo .mp3 (10 min.).
} 


\section{O bairro Nossa Senhora Aparecida: aparecimento das primeiras políticas públicas}

O advento da energia elétrica nas imediações do bairro NSA, no ano de 1970, foi a primeira política pública ali implantada. Isso representou uma conquista relevante para os entrevistados que vivem há tanto tempo naquele espaço urbano, uma vez que candeeiros eram usados pelos primeiros moradores. Havia ainda a dificuldade de locomoção dos transeuntes e dos veículos pelas ruas não pavimentadas, sobretudo, por conta da preocupação com assaltos, roubos e outros crimes e delitos.

Analisando os dados fornecidos pelo Censo Demográfico de 2010, pode ser observado que o percentual de domicílios que possuíam rede de energia elétrica foi aumentado para 99,58\%, o que é um ponto forte, pois esse resultado indicou que o bairro NSA dispõe na atualidade de uma boa infraestrutura em relação ao acesso aos serviços de energia elétrica, conforme indicado na Tabela 2.

Tabela 2 - Existência de rede elétrica - Bairro NSA (2010).

\begin{tabular}{lcl}
\hline Existência de redeelétrica & $\begin{array}{c}\text { Quantidade de } \\
\text { domicílios }\end{array}$ & $\%$ \\
\hline Total & 961 & \\
Tinham & 957 & 99,58 \\
Nãotinham & 4 & 0,42 \\
\hline
\end{tabular}

Fonte: IBGE Censodemográfico, 2010.

Durante os anos 70, foi instalada a primeira escola de Ensino Fundamental naquele bairro, com funcionamento em uma Igreja que fora construída em regime de mutirão. Contudo, após a instalação da Escola Nossa Senhora Aparecida, o Poder Público local e o Estadual assumiram sua gestão administrativa e pedagógica.

Depois do surgimento da energia elétrica e da instalação da escola no bairro, o Poder Público construiu na década de 1980 cerca de 75 (setenta e cinco) cisternas, posto que aquele bairro não possuía serviço de abastecimento de água.

Ficou constatado que até o ano de 1995 os moradores do bairro NSA utilizavam cisternas, consoante com a Figura 1.

Em atendimento às reivindicações dos moradores, no ano de 1995, o bairro NSA foi interligado ao sistema de abastecimento de água, gerenciado pela Empresa Baiana de Águas e Saneamento (EMBASA). 
Figura 1- Fila para coletar água na casa de Dona Josina (1985).

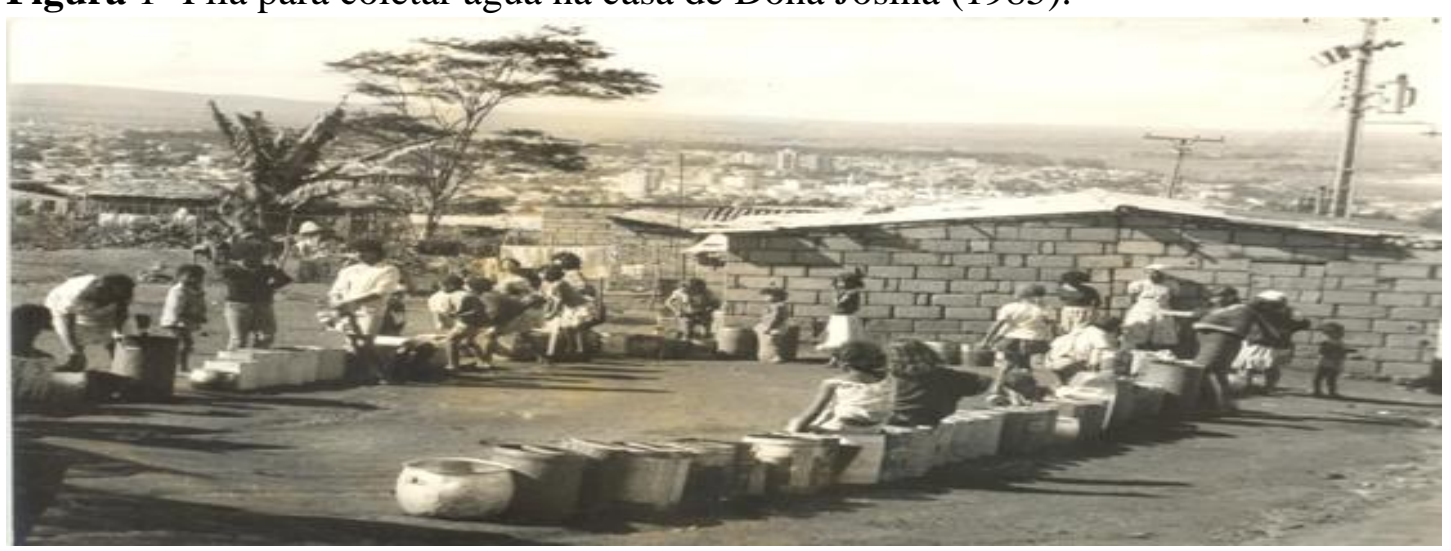

Fonte: PMVC (2012) - Arquivo municipal.

A Tabela 3 mostra que aumentou para 96,57\% o número de domicílios com abastecimento de água, de acordo com o Censo Demográfico de 2010, o que implica dizer que dos 961 domicílios, 928 são atendidos com a rede geral de água.

Tabela 3 - Abastecimento de água no Bairro NSA (2010).

\begin{tabular}{lrr}
\hline Forma de abastecimento de água & $\begin{array}{c}\text { Quantidade de } \\
\text { domicílios }\end{array}$ & $\%$ \\
\hline Total & 961 & 96,57 \\
Redegeral (pública) & 928 & 0,21 \\
Poço ou nascente na propriedade & 2 & 1,87 \\
Poço ou nascente fora da propriedade & 18 & 0,00 \\
Carro-pipa ou água da chuva & - & 0,00 \\
Rio, açude, lago ou igarapé & - & 0,00 \\
Poço ou nascente na aldeia & - & 0,00 \\
Poço ou nascente fora da aldeia & - & 1,35 \\
Outra & 13 & \\
\hline
\end{tabular}

Fonte: IBGE Censodemográfico, 2010.

Outro marco no bairro aconteceu nos anos de 1982, quando houve a instalação de um telefone público, momento muito festado pelos moradores daquela localidade. Ressalta-se que naquela década, dispor de um telefone público representava a possibilidade de evitar o deslocamento até outro bairro e reduzia as dificuldades de comunicação entre as pessoas que residiam distantes de seus parentes, amigos ou até mesmo para comunicar-se com outros em busca de serviços e outras demandas. Por muito tempo, ter um telefone particular era bem difícil e seletivo devido ao alto custo da linha e do equipamento, diferentemente de hoje em dia que há a facilidade de qualquer um obter um aparelho de baixo custo, com diversificadas formas de pagamento do plano da linha e de aparelhos fixos e celulares que tornaram populares. 
Ainda no ano de 1982, a instalação de um minadouro de água foi um serviço essencial para o bairro NSA. Varges e Marinho (2004, p. 43) salientaram que "a Serra do Periperi funciona como uma esponja que capta a água das chuvas, formando um expressivo lençol d'água, extremamente favorável ao afloramento freático, na forma de pontos de surgência que correspondem inúmeras nascentes", e assim, a água de seus afloramentos é direcionada para o abastecimento de minadouros como os dos bairros NSA e Panorama.

Em 1984, a Prefeitura Municipal de Vitória da Conquista realizou o plantio de 35 mil mudas de eucalipto na parte lateral do bairro NSA, onde antes existiam as propriedades denominadas de Fazenda Lisboa e Pombal, numa área de 36 hectares.

As obras de calçamento foram realizadas nas quatro principais ruas do bairro NSA. O calçamento foi em pedras. Logo em seguida, a pavimentação dessas ruas, aumentou a ocupação demográfica do bairro. $\mathrm{O}$ aparecimento e o desenvolvimento da periferia são desencadeados devido tanto ao processo de urbanização quanto à expansão da malha urbana, aliados à segregação socioespacial. No Brasil, a periferização deixou de ser restrita às metrópoles desde as décadas de 1950 a 1970, quando houve uma explosão de discussões em torno da temática periferia, e com isso, esse fenômeno passou a ser visto nas cidades médias (SPOSITO, 2004). Para Corrêa (1989) a urbanização se dá de forma distinta para cada classe, podendo se manifestar dois tipos de urbanização: 1) de status, 2) popular. A primeira diz respeito à classe dominante, pois esta recebe a infraestrutura necessária, embora esteja localizada distante do centro, não é vista como periférica pois estes bairros concentram a população mais rica. No segundo caso, ocorre o oposto, seus moradores são pauperizados e não desfrutam de uma infraestrutura adequada, e mesmo que não se limitem ao centro, serão percebidos como periféricos. Tessari; Braga (2008) complementam que os investimentos para esses bairros periféricos demoram por conta da condição econômica ou localização e também pela posição na periferia das políticas públicas.

Na década de 1990, a principal obra realizada foi a construção de um canal para desvio das águas das chuvas que causava sérios problemas para a infraestrutura física do bairro, localizada na Serra do Periperi, na parte alta.

O bairro NSA foi contemplado com algumas ações positivas provenientes do Orçamento Participativo implementado pela Prefeitura Municipal de Vitória da Conquista, em 1999, dentre elas destacam-se a construção do canal de drenagem; a Instalação da Unidade de Saúde da Família (USF); a pavimentação asfáltica do trecho que faz a interligação entre as Ruas Santa Cecília e Santa Rita com a BR-116 (Avenida Integração, antiga Rodovia Rio- 
Bahia) e a pavimentação em pedra da Rua São Sebastião; e a construção do Centro Municipal de Educação Infantil Frei Graciano de Santo Elpídio, creche de referência na localidade.

Guilherme Menezes de Andrade, durante seu mandato (2012-2016) como Prefeito de Municipal de Vitória da Conquista, em entrevista pronunciou:

No NSA, foi até uma moça chamada Daiana que, numa Roda de Conversa, falou sobre uma demanda antiga do OP para aquele bairro. A referida jovem reforçou a solicitação da creche do bairro Aparecida, que já está em fase de conclusão. Atualmente, estamos construindo 11 creches na cidade, em localidades onde a mãe e o pai precisam sair para trabalhar e necessitam deixar seus filhos em local seguro, com pessoas qualificadas. Isso gera uma qualidade de vida, uma tranquilidade para os pais, pois sabem que, chegando tarde do trabalho, vão encontrar suas crianças alimentadas, limpas, bem cuidadas, num ambiente socializador. Uma creche é um tipo de primeira escola que deve receber atenção especial do Poder Público (CARVALHO, 2015, p. 26).

O Centro Municipal de Educação Infantil Frei Graciano de Santo Elpídio possui 172 alunos (do maternal I ao II período) matriculados no ano de 2017, com funcionamento nos turnos matutino e vespertino, segundo relato em entrevista realizada no mesmo ano.

\section{Políticas Públicas de Desenvolvimento Social}

Em termos de assistência social, o Programa de Erradicação do Trabalho Infantil (PETI), Bolsa Família e Projovem Adolescente e Urbano são os principais programas sociais implantados no bairro NSA.

O PETI é parte do Sistema Único de Assistência Social (SUAS) com duas ações articuladas: o Serviço Socioeducativo ofertado para as crianças e adolescentes encontrados em trabalho precoce e a Transferência de Renda para suas famílias. As ações socioassistenciais ofertadas são direcionadas à família, potencializando a sua função protetiva e os vínculos familiares e comunitários. Objetiva corroborar para a erradicação de todas as formas de trabalho infantil no País, com um atendimento focado às famílias cujas crianças e adolescentes com idade inferior a 16 anos (entre 7 a 15 anos), estejam em situação de trabalho. O PETI está inserido em um processo de resgate da cidadania e promoção de direitos de seus usuários, bem como de inclusão social de suas famílias. Funciona no município desde o ano de 2000 (PMVC, 2012).

No município de Vitória da Conquista, o programa atende em média 2 mil crianças e adolescentes e conta com 36 núcleos de jornadas ampliadas, sendo que 13 núcleos funcionam 
na zona urbana e 23 nos distritos da zona rural. Quanto ao quantitativo de pessoal, o PETI atendeu uma média 110 crianças em cada ano, no bairro NSA (PMVC, 2012).

\section{O Programa Bolsa Família (PBF)}

O Bolsa Família faz parte do Programa Fome Zero do Governo Federal, que visa assegurar a segurança alimentar e nutricional, para minimização da erradicação da extrema pobreza. Além disso, este programa pretende promover a transferência direta de renda para amparar famílias que se encontrem em situação de pobreza ou extrema pobreza, em concordância com a Lei n. ${ }^{\circ}$ 10.836, de 9 de janeiro de 2004 e o Decreto n. ${ }^{\circ}$ 6.917, de 30 de julho de 2009. Há dois tipos de benefício variável: 1) Famílias com crianças e adolescentes de até 15 anos (até o limite de três); 2) Famílias com jovens de 16 e 17 anos frequentando a escola (até o limite de dois). Esse é o benefício variável vinculado ao adolescente (BVJ) (PMVC, 2012).

No Manual de Gestão do Programa Bolsa Família, material informativo do Ministério do Desenvolvimento Social e Combate à Fome (MDS), o PBF atua com base em três dimensões essenciais à superação da fome e da pobreza, se pensadas de modo articulado: $1^{\mathrm{a}}$ ) promoção do alívio imediato da pobreza, por meio da transferência direta de renda à família; $2^{\text {a }) ~ a m p l i a c ̧ a ̃ o ~ d o ~ e x e r c i ́ c i o ~ d e ~ d i r e i t o s ~ s o c i a i s ~ b a ́ s i c o s ~ n a s ~ a ́ r e a s ~ d e ~ s a u ́ d e ~ e ~ e d u c a c ̧ a ̃ o, ~}$ direcionado pelo cumprimento das condicionalidades, o que, na avaliação do Governo Federal deveria contribuir para que as famílias rompessem com o ciclo da pobreza entre as gerações;

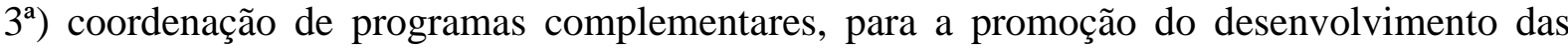
famílias, de modo que os beneficiários do Bolsa Família sejam auxiliados para superar a situação de vulnerabilidade e pobreza (BRASIL, 2015).

Na realização do estudo de caso no bairro NSA foi constatado que, nos últimos anos, o Programa Bolsa Família recebeu em torno de 1.300 bolsas. Contudo, embora esteja aliado a outros programas implantados no município de Vitória da Conquista, não foram localizadas evidências que comprovem que o programa está favorecendo ao rompimento do ciclo da pobreza pelos moradores do bairro NSA.

\section{Projovem adolescente e urbano}

O Projovem visa complementar a proteção social básica à família, desenvolvendo mecanismos para garantir a convivência familiar e comunitária e elaborando condições para a (re)inserção e permanência do jovem no sistema de educação. 
Trata-se de uma modalidade do Programa Nacional de Inclusão de Jovens (Projovem) voltada, exclusivamente, para os jovens com faixa etária entre os 15 a 17 anos (BRASIL, 2008).

É um serviço socioeducativo de convívio de assistência social, que integra as ações de proteção social básica do Sistema Único de Assistência Social (SUAS). Atende, em média, 450 jovens, em 18 grupos. No bairro NSA participam do Projovem Adolescente em torno de 60 jovens a cada ano.

O Projovem Urbano trabalha com jovens na faixa etária de 18 a 29 anos, que abandonaram os estudos, abrange a educação básica e objetiva promover a inclusão ao mercado de trabalho de jovens com baixa escolaridade (SALGADO, 2012).

\section{Política de saúde}

Foi averiguado que no bairro Nossa Senhora Aparecida somente há a cobertura local de programas de Saúde Básica, Saúde Bucal e Assistência Farmacêutica (limitando-se a distribuição básica de alguns medicamentos indicados no momento das consultas médicas). Os demais programas coordenados pela Secretaria Municipal de Saúde têm cobertura geral (seja com unidades centrais que prestam o atendimento à toda população conquistense ou com unidades para prestar o atendimento em outros bairros da cidade).

De acordo com Travassos e Martins (2004), o acesso e o uso de serviços de saúde podem estar sujeitos à/ao/s: a) oferta e demanda; b) acessibilidade geográfica (vias de acesso, localização, transporte público); c) padrões de atendimento e procedimentos de conduta; d) cobrança de taxas pelos serviços; e) modo de organização e funcionamento da unidade ofertadora dos serviços de saúde.

\section{Política de Educação}

Percebeu-se que duas unidades escolares foram instaladas no bairro NSA: o Centro Municipal de Educação Infantil Frei Graciano de Santo Elpídio ${ }^{2}$ (Creche e Pré-escola) e a Escola Nossa Senhora Aparecida (Ensino Fundamental), ambas sob responsabilidade do poder municipal.

\footnotetext{
${ }^{2}$ Inaugurado no dia 10 de dezembro de 2012, pelo Prefeito Guilherme Menezes.
} 
$\mathrm{Na}$ área de Educação, dentre os programas públicos da cidade de Vitória da Conquista, verificou-se a presença no bairro dos seguintes programas: Desenvolvimento da Educação Infantil, Desenvolvimento do Ensino Fundamental e Alimentação escolar. Já em relação aos Programas de atendimento ao estudante e transporte escolar, de Inovações e tecnológicas educacionais, e de Desenvolvimento da educação especial não foram constatadas ações efetivas naquele bairro.

\section{Considerações finais}

As evidências coletadas a partir do resgate do passado do bairro NSA, mediante as representações de espaço e tempo, por intermédio da memória e da história, mostraram que a infraestrutura física do bairro NSA é precária, caracterizada por moradias construídas na modalidade de autoconstrução. As ruas do bairro possuem um traçado que surgiu de modo espontâneo, sem observar a legislação inerente ao uso e ocupação do solo urbano. Há sérios problemas de drenagem nas ruas, falta de pavimentação e esgotamento sanitário em algumas áreas do bairro.

Quanto aos aspectos sociais do bairro NSA, merece ser destacado que foi revelado o forte significado que os moradores atribuem aos vínculos familiares, à amizade, à igreja, aos laços de solidariedade, confirmando a hipótese de que o espaço urbano estudado mantém forte inter-relação com a memória dos moradores e as representações sociais.

Ademais, este trabalho se limitou apenas à análise de um bairro periférico pobre da cidade de Vitória da Conquista. Por isso, recomenda-se a realização de trabalhos futuros para dar continuidade ao processo investigativo de produção do espaço urbano desta cidade.

\section{Referências}

BENEDICTIS, N. M. S. M. Política ambiental e desenvolvimento urbano na Serra do Periperi em Vitória da Conquista - BA. 2007. 107f. Dissertação (Mestrado em Ciências Sociais). Universidade Federal do Rio Grande do Norte, 2007.

BOSI, E. Memória e sociedade: lembranças de velhos. São Paulo: T. A. Queiroz, 1994.

BRASIL. Decreto n. ${ }^{\circ}$ 6.917. Altera os arts. 18, 19 e 28 do Decreto n. ${ }^{\circ} 5.209$, de 17 de setembro de 2004, que regulamenta a Lei n. ${ }^{\circ} 10.836$, de 9 de janeiro de 2004, que cria o Programa Bolsa Família, 30 de julho de 2009. Brasília-DF, 2009. Disponível em: <http://www.planalto.gov.br/ccivil_03/_Ato2007-2010/2009/Decreto/D6917.htm\#art3>. Acesso em: 01 ago. 2017. 
Lei n. ${ }^{0}$ 10.836. Cria o Programa Bolsa Família e dá outras providências, 09 de janeiro de 2004. Brasília-DF, 2004. Disponível em: <http://www.planalto.gov.br/ccivil_03/_ato2004-2006/2004/lei/110.836.htm>. Acesso em: 16 ago. 2017.

Lei n. ${ }^{\circ}$ 11.692.Dispõe sobre o Programa Nacional de Inclusão de Jovens - Projovem, instituído pela Lei n ${ }^{\circ} 11.129$, de 30 de junho de 2005 e dá outras providências, 10 de junho de 2008. Brasília-DF, 2008. Disponível em: <http://www.planalto.gov.br/ccivil_03/_ato20072010/2008/lei/111692.htm>. Acesso em: 20 maio. 2017.

Manual de gestão do Programa Bolsa Família. 2. ed. atualizada. Ministério do Desenvolvimento Social e Combate à Fome (MDS), Secretaria Nacional de Renda de Cidadania (Senarc). Brasília-DF, 2015. Disponível em: $<$ ftp://ftp.mds.gov.br/externo/ead/outros/arquivos_a_enviar/MIOLO\%20\%20Manual_Gestao_Bolsa_Familia_18082015\%20-\%20print.pdf >. Acesso em: 26 jul. 2017.

CARLOS, A. F. A. Espaço-tempo na metrópole. São Paulo: Contexto, 2001.

CARVALHO, F. S. Envolvimento dos moradores no Orçamento Participativo da cidade de Vitória da Conquista: o caso do bairro Nossa Senhora Aparecida. Caderno de Ciências Sociais Aplicadas. Vitória da Conquista - BA, n. 19, p. 13-38, 2015.

CHAUÍ, M. de. S. Os trabalhos da memória. In: Memória e sociedade: lembranças de velhos. São Paulo: T. A. Queiroz, 1979.

CORRÊA, R. L.O espaço urbano. São Paulo: Ática, 1989.

CUSTÓDIO NETO, R. Raimundo Custódio Neto. Depoimento [2012]. Vitória da Conquista, Bahia, 2012. Mídia digital sonora. Entrevista concedida.

HAESBAERT, R. Da multiterritorialidade aos novos muros:paradoxos da desterritorialização contemporânea. 2011. Disponível em:

$\langle$ http://www.posgeo.uff.br/sites/default/files/da_multiterritorialidade_aos_novos_muros.pdf $\rangle$. Acesso em: 5 ago. 2017.

O mito da desterritorialização:do fim dos territórios a multiterritorialidade. Rio de Janeiro: Bertrand Brasil, 2007.

HAGUETTE, T. M. F. Metodologias qualitativas na sociologia. 5. ed. Petrópolis: Vozes, 1997.

MAIOLINO, A. L. G.; MANCEBO, D. Análise histórica da desigualdade, marginalidade, segregação e exclusão.Psicologia \& Sociedade, Porto Alegre, v. 17, n. 2, 2005. Disponível em: <http://www.scielo.br/scielo.php?script=sci_arttext\&pid=S010271822005000200003\&lng=pt>. Acesso em: 12 jul. 2017.

PESAVENTO, S. J. Cidade, Espaço e Tempo: Reflexões sobre a Memória e o Patrimônio Urbano. Cadernos do LEPAARQ - Textos de Antropologia, Arqueologia e Patrimônio.v. 2, n. 4. Pelotas, RS: Editora da UFPEL. ago/dez 2005.

PREFEITURA MUNICIPAL DE VITÓRIA DA CONQUISTA. Arquivo municipal. Base documental. 2012. 
SALGADO, M. U. C. (org.). Manual do educador: orientações gerais. Projovem urbano. Orientações gerais. Brasília: Programa Nacional de Inclusão de Jovens - Projovem Urbano, 2012. 216p.: il. - (Coleção Projovem Urbano).

SANTOS, M. A natureza do espaço: técnica e tempo, razão e emoção. São Paulo: EDUSP, 2002. (Coleção Milton Santos, 1)

O espaço do cidadão. São Paulo: Nobel, 1996.

SPOSITO, M. E. B. Novos conteúdos nas periferias urbanas das cidades médias do estado de São Paulo, Brasil. In: Investigações Geográficas, UNAM, 2004, n. 54, p. 114-139.

TESSARI, L. M.; BRAGA, R. Segregação e periferização urbana em cidades pequenas: o caso de Gavião Peixoto/SP. In: Geoambiente on-line, Jataí/GO, n. 10, 2008, p. 214-231.

TRAVASSOS, C.; MARTINS, M. Uma revisão sobre os conceitos de acesso e utilização de serviços de saúde. Caderno Saúde Pública. 20(2): Rio de Janeiro, 2004.

TRIVINOS, A. M. Introdução à pesquisa em ciências sociais: a pesquisa qualitativa em educação. São Paulo: Atlas, 1997.

VARGES, M. de S.; MARINHO, P. dos S. Urbanização e degradação dos recursos hídricos: estudo das águas superficiais no perímetro urbano de Vitória da Conquista, Bahia. Monografia (Graduação). UESB - Universidade Estadual do Sudoeste da Bahia: ago, 2004.

YIN, R. K. Estudo de Caso, planejamento e métodos. 2. ed. São Paulo: Bookman, 2005.

Recebido em: 22/10/2017

Aceito para publicação em: 30/11/2017 